\title{
Kolagenozni gastritis pri otrocih
}

\section{Collagenous gastritis in children}

Tjaša Nanut, Nina Zidar, Darja Urlep

\section{Izvleček}

Kolagenozni gastritis je redka oblika kroničnega vnetja želodčne sluznice. Diagnozo postavimo na podlagi značilnega histopatološkega izvida, ki pokaže zadebeljeno subepitelno kolagensko plast v lamini propriji želodčne sluznice. Poznamo dva fenotipa bolezni - otroško in odraslo obliko. Kolagenozni gastritis $v$ odrasli dobi je značilno povezan s kolagenoznim kolitisom in drugimi avtoimunskimi boleznimi. Otroška oblika se najpogosteje kaže $z$ anemijo s pomanjkanjem železa in bolečinami v epigastriju. Patogeneza bolezni je nejasna, zato tudi ne poznamo učinkovitega zdravljenja. $V$ prispevku predstavljamo primer deklice s kolagenoznim gastritisom, ki smo jo zdravili na Kliničnem oddelku za gastroenterologijo, hepatologijo in nutricionistiko Pediatrične klinike v Ljubljani.

Ključne besede: gastritis, kolagen, sideropenična anemija, epigastrična bolečina, otroci.

\begin{abstract}
Collagenous gastritis is a rare type of chronic inflammation of the gastric mucosa. The diagnosis is based on histological proof of thickening of the subepithelial collagen layer in the lamina propria of the gastric mucosa. There are two known phenotypes of collagenous gastritis: paediatric and adult types. The adult-onset form is associated with collagenous colitis and other autoimmune disorders. The most common clinical presentations of the paediatric form are iron deficiency anaemia and epigastric pain. The pathogenesis of the disease remains unclear and hence no effective treatment has been found yet. We report a case of a girl who presented with collagenous gastritis and was treated in the Department of Gastroenterology, Hepatology and Nutrition of the University Children's Hospital Ljubljana.
\end{abstract}

Key words: gastritis, collagen, iron deficiency anaemia, epigastric pain, children. 


\section{Uvod}

Kolagenozni gastritis (KG) je zelo redka oblika kroničnega vnetja želodčne sluznice. Uvrščamo ga med kolagenozne gastroenteritise, med katere sodita tudi kolagenozni kolitis in kolagenozna "sprue" (1-3). Za omenjene bolezni je značilno subepitelno kopičenje kolagena $z$ vnetno inflitracijo lamine proprije z mononuklearnimi celicami (2). Najpogostejša oblika je kolagenozni kolitis, ki je oblika mikroskopskega kolitisa s subepitelnim kopičenjem kolagena in endoskopsko normalno sluznico debelega črevesa (4). Redkejši obliki sta KG in kolagenozna "sprue". Pri kolagenozni "sprue" je kolagensko vezivo umeščeno $v$ predelu tankega črevesa (3), pri KG pa v predelu želodca (1-5). Za kolagenozni kolitis, ki se pogosteje pojavlja v odraslosti, so značilne kronične vodene driske in bolečine $v$ trebuhu (4). V letu 1989 so prvič opisali otroško obliko KG pri petnajstletni deklici s ponavljajočimi se bolečinami v žlički in znaki krvavitve iz zgornjih prebavil (6). Hijaz in sodelavci so opisali 24 pediatričnih bolnikov s KG, pri štirih pa so ugotavljali pridruženi kolagenozni kolitis (7). KG je lahko povezan tudi z drugimi imunsko posredovanimi boleznimi (celiakija, sladkorna bolezen, avtoimunski hipotiroidizem, Sjögrenov sindrom, sistemski eritematozni lupus, ulcerozni kolitis) (1, 5, 7-10).

\section{Klinične značilnosti}

Klinična slika otroške oblike KG se razlikuje od odrasle. Nekateri menijo, da bi lahko šlo za spekter iste bolezni, saj opisujejo primere odraslega fenotipa tudi pri otrocih $(7,11)$. Klasična otroška oblika značilno nastane pred puberteto, nekoliko pogosteje pri deklicah. Začetna klinična slika se kaže $z$ bolečinami v trebuhu, predvsem $z$ bolečino $v$ žlički, dispeptičnimi simptomi, lahko tudi z bruhanjem, in zelo pogosto s slabokrvnostjo zaradi pomanjkanja železa (7, 11-15). Pri odrasli obliki KG je običajno prisotna vodena driska $z$ izgubo telesne teže zaradi pridruženega kolagenoznega kolitisa $(1-2,5)$.
Endoskopske in patohistološke značilnosti

Pri endoskopskem pregledu najdemo značilne hiperplastične nodule želodčne sluznice, prisotna sta lahko tudi edem in eritem, pogosto celo erozije in ulkusi $(16,17)$. Podobno nodularno sluznico najdemo tudi pri drugih gastropatijah, predvsem pri gastritisu, povzročenem z bakterijo Helicobacter pylori (HP). Diagnozo postavimo na podlagi značilnih patohistoloških sprememb želodčne sluznice (16-18). Pri odraslih bolnikih so nodularne spremembe želodčne sluznice lahko slabo izražene ali celo odsotne, histološko pa dokažemo obsežne spremembe $s$ subepitelnimi kolagenoznimi odlagami in vnetnim infiltratom v lamini propriji $(5,16-18)$. Zanimivo je, da so patohistološke spremembe intenzivneje izražene ob nodusih želodčne sluznice, kjer je sluznica atrofična s spremenjenimi drobnimi žilami, ki so lahko razširjene ali zožene (16-18). Kolagenski trački, ki so debelejši od $10 \mu \mathrm{m}$, so značilen diagnostični znak KG, njihova debelina pa lahko presega $100 \mu \mathrm{m}(17,18)$.

Zaradi neenakomernega vnetja želodčne sluznice moramo pri endoskopskem pregledu odvzeti več biopsijskih vzorcev. Vzorce odvzamemo tudi v okolici nodusov, da zajamemo sluznico $z$ bolj intenzivnimi spremembami $(4,5,11)$.

\section{Etiopatogeneza}

Etiologija KG je nepojasnjena. Obstajajo različne hipoteze. V nastanek bolezni je lahko vpletenih več dejavnikov, lahko gre za infekcijske, alergene ali medikamentozne sprožilce $(1,2,18)$. Po eni od hipotez je primarni vnetni proces posledica imunsko posredovanega vnetja, ki vodi v nastanek kolagenoznega veziva $(6,7,18,19)$. Ugotovili so namreč prekomerno izražena humani levkocitni antigen DR in antigen $\mathrm{CD} 25$, kar govori v prid omenjeni hipotezi $(6,7)$. Nekateri menijo, da gre pri KG za primarno žilno motnjo s povečano prepustnostjo, ki vodi v zunajžilno odlaganje beljakovin (7).

\section{Zdravljenje}

Zaradi majhnega števila primerov bolezni nimamo na voljo randomiziranih kontroliranih raziskav in zato tudi ne poznamo uspešnega zdravljenja ( 7 , 11). $V$ opisanih primerih so najpogosteje uporabljali zaviralce protonske črpalke (ZPČ) $(1-2,5,7,11,14)$. Slabokrvnost so zdravili s pripravki železa, pogosto je bilo potrebno dolgotrajnejše nadomeščanje $(1,2,7,11,13)$. Pri posameznih bolnikih so poskušali zdravljenje s sukralfatom, mesalazinom, sulfasalazinom, bizmutovim subsalicilatom in furazolidonom, a uspešnosti omenjenih zdravljenj niso potrdili $(6,7,20)$. Do sedaj so opisali posamezne primere uspešno zdravljenih otrok s hipoalergenimi in brezglutenskimi dietami (11, 21), prav tako posamezne primere, pri katerih so bili učinkoviti kortikosteroidi $(7,11,22)$. Kortikosteroidi so imeli boljši učinek ob pridruženem kolagenoznem kolitisu $(1,11)$. Matta s sodelavci so opisali dvanajst otrok $s$ KG in le pri enem otroku, ki je imel pridružen kolagenozni kolitis, so ugotavljali klinično, endoskopsko in histopatološko izboljšanje po zdravljenju s kortikosteroidi in azatioprinom (11). Enajst otrok je zaradi slabokrvnosti prejemalo oralne pripravke železa, štirje pa ZPČ. Pri štirih otrocih so uvedli hipoalergeno dieto, a v večini primerov po prehranskem zdravljenju niso ugotavljali izboljšanja (11).

\section{Potek bolezni}

Nejasna sta tudi potek in prognoza bolezni. Za KG je značilno neskladje med klinično benignim potekom bolezni in histopatološkim izvidom $(5,7,11)$. Pri večini primerov so opisali postopno napredovanje patohistoloških sprememb $(1,2,5,17)$ pa tudi posamezne primere bolnikov z bolj ugodno prognozo. Lagorce-Pages in sodelavci so predstavili primer odraslega bolnika s KG in pridruženim kolagenoznim kolitisom, ki so ga zdravili s kortikosteroidi, parenteralno prehrano in salazopirinom. Po treh mesecih zdravljenja niso več ugotavljali kolagenskih depozitov v sluznici želodca, 


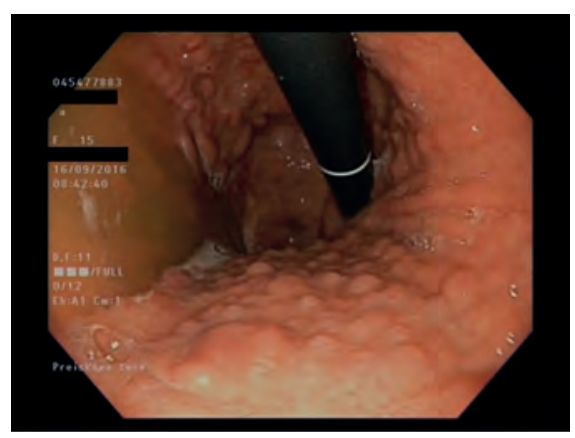

SLIKA 1. ENDOSKOPSKI PRIKAZ NODULARNEGA VIDEZA ŽELODČNE SLUZNICE.

FIGURE 1. ENDOSCOPIC DEMONSTRATION OF THE NODULAR APPEARANCE OF THE GASTRIC MUCOSA.

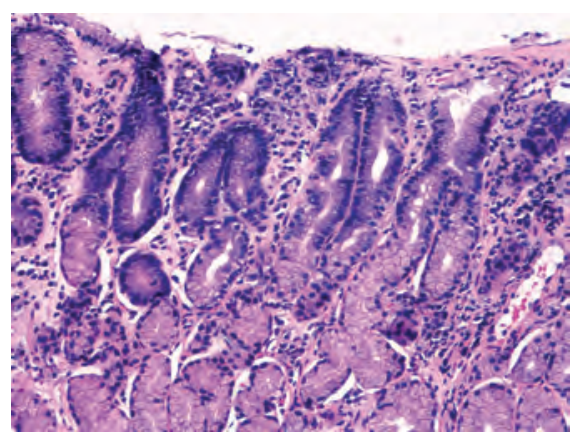

SLIKA 2A. BIOPSIJSKI VZOREC ŽELODČNE SLUZNICE ANTRALNEGA TIPA Z NEENAKOMERNO POMNOŽENIM KOLAGENSKIM VEZIVOM POD DELNO OLUŠČENIM VRHNJIM EPITELOM.

FIGURE 2A. BIOPSY SAMPLE OF THE ANTRAL GASTRIC MUCOSA, WITH APPARENT IRREGULAR COLLAGEN DEPOSITS UNDER THE PARTIALLY EXFOLIATED EPITHELIAL COVER.

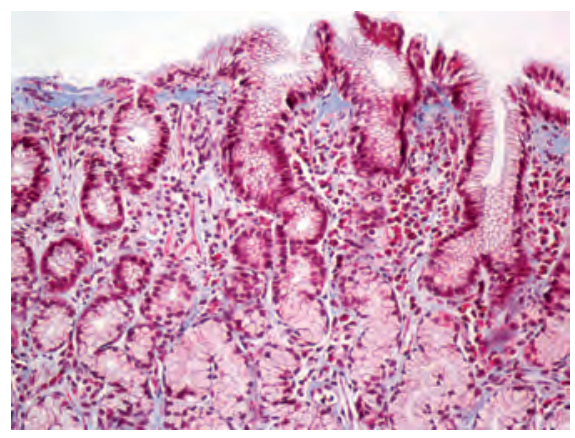

SLIKA 2B. V TRIKROMNEM BARVANJU PO MASSONU SE POMNOŽENO VEZIVO POD EPITELOM OBARVA MODRO.

FIGURE 2B. AFTER APPLYING THE TRICHROMATIC MASSON STAIN, THE SUBEPITHELIAL COLLAGEN DEPOSITS TURN A BLUE COLOUR. po dveh letih pa so depoziti kolagena izginili tudi v sluznici kolona (23). Hijaz in sodelavci so opisali primer dečka, kjer so depoziti kolagena izginili po petih letih zdravljenja z ZPČ in nadomeščanjem železa (7). Opisali so tudi primer otroške oblike KG, pri katerem je prišlo do intestinalne metaplazije in hiperplazije endokrinih celic, kar bi morda kasneje lahko privedlo do rakavih sprememb (7).

\section{Prikaz kliničnega primera}

Trinajstletna deklica je bila sprejeta na kardiološki oddelek Pediatrične klinike v Ljubljani zaradi tiščanja v prsnem košu in zadihanosti ob naporu. Izključili so kardiogeni vzrok težav. Ugotavljali so hudo mikrocitno anemijo. Zaradi suma na prikrito krvavitev iz prebavil je bila premeščena na Klinični oddelek za gastroenterologijo, hepatologijo in nutricionistiko (KOGHN). Do sprejema na KOGHN je bila zdrava, simptomov s strani prebavil ni imela. Primerno je napredovala na telesni teži in višini. V družini nimajo imunsko posredovanih bolezni, starejši sorojenec je bil pred leti zdravljen zaradi eozinofilnega vnetja požiralnika. Ob sprejemu razen izrazite bledice in sistolnega šuma nad prekordijem nismo našli odstopanj v kliničnem statusu. V laboratorijskih izvidih smo ugotavljali hudo mikrocitno anemijo (Hb 36g/l, Ht 13,8\%, MCV 61,4, MCH 15,9, MCHC 254), vsi ostali laboratorijski izvidi so bili normalni. Specifična protitelesa IgE na kravje mleko, jajca, gluten in oreščke so bila negativna. Zaradi suma na krvavitev iz prebavil smo opravili gastroduodenoskopijo (EGDS), ileokolonoskopijo in kapsulno endoskopijo. Izvida kapsulne endoskopije in ileokolonoskopije sta bila normalna, patohistološko smo izključili tudi kolagenozni kolitis. Z EGDS smo ugotavljali izrazito nodularno, edematozno in eritematozno sluznico celotnega želodca (Slika 1), medtem ko sta bili sluznica požiralnika in dvanajstnika normalni. Patohistološko ter z dodatnimi usmerjenimi preiskavami smo izključili HP gastritis, celiakijo, morebitno vnetje zgornjih prebavil v sklopu Crohnove bolezni in druge bolezni sluznice zgornjih prebavil. Patohistološki izvid biopsijskih vzorcev sluznice želodca je pokazal zadebeljeno plast subepitelnega kolagenoznega veziva (Sliki $2 a$ in $2 b$ ) in potrdil diagnozo kolagenoznega gastritisa. Uvedli smo zdravljenje z zaviralci protonske črpalke (ZPČ). Anemijo smo pozdravili s parenteralnim železom. Deklico smo nato klinično, laboratorijsko in endoskopsko spremljali vse do odraslosti. V tem času je prejemala ZPČ in bila vseskozi brez simptomov pa tudi slabokrvnost se ni več pojavila. Ker se endoskopski in patohistološki izvid nista izboljševala, smo poskusno uvedli dieto brez kravjega mleka, jajc, glutena, soje in oreščkov. Po osmih mesecih dietnega zdravljenja so se nodularne spremembe želodčne sluznice zmanjšale in tudi kolagenska plast se je z začetne vrednosti 40-100 $\mu \mathrm{m}$ zmanjšala na $25 \mu \mathrm{m}$. Ker smo želeli doseči endoskopsko in patohistološko remisijo, smo se skupaj z deklico in starši odločili še za poskus zdravljenja s kortikosteroidi. Po treh mesecih zdravljenja smo ugotovili endoskopsko izboljšanje, nodularnost želodčne sluznice je bila bistveno manj izražena, ob tem pa je patohistološki izvid ostal nespremenjen (kolagenska plast debeline 20-25 $\mu \mathrm{m}$ ). Deklica je bila po petih letih zdravljenja povsem brez težav, slabokrvnost se ni ponovila.

\section{Razpravljanje}

V prispevku smo opisali diagnosticiranje in zdravljenje kolagenoznega gastritisa (KG) pri trinajstletni deklici, ki je v Sloveniji prvi primer te redke bolezni, diagnosticiran že v otroški dobi. Zanimivo je, da je bila deklica sprva obravnavana na kardiološkem oddelku, saj ni imela simptomov s strani prebavil, ampak le težave zaradi hude mikrocitne anemije. Tudi v literaturi opisujejo, da se pri otro- 
ški obliki KG najpogosteje pojavljajo simptomi mikrocitne anemije $(7,11$, 13). Slabokrvnosti se pogosto pridružijo bolečine $v$ žlički in drugi dispeptični simptomi $(7,11-15)$. Ker so tudi v otroški dobi opisani primeri bolnikov s pridruženim kolagenoznim kolitisom, smo pri deklici izključili kolagenozni kolitis ob sprejemu in tudi kasneje ob poteku bolezni. Izključevali smo tudi druge imunsko posredovane ali avtoimunske bolezni. Med spremljanjem je deklica začela navajati obdobja z izrazito mrzlimi in modrikastimi prsti rok. Revmatologi so opravili obnohtno kapilaroskopijo in dokazali Raynaudov sindrom, ki je lahko predhodnik imunsko posredovane bolezni (24). Deklico bo zato potrebno slediti tudi $s$ te strani. Ne glede na zaenkrat še nepojasnjeno patogenezo bolezni se zdi precej verjetna hipoteza, da gre pri KG za imunsko posredovano vnetje, ki vodi v nastanek kolagenskega veziva $(6,7,18,19)$.

Učinkovitega zdravljenja za zdaj ne poznamo. Bolnike zdravimo empirično, najpogosteje z ZPČ $(1-2,5,7,11$, 14). Zdravljenje z ZPČ pri naši deklici ni privedlo do remisije bolezni, zato smo poskusili s hipoalergeno dieto, kasneje tudi s peroralnimi kortikosteroidi. Z omenjenimi načini zdravljenja smo dosegli endoskopsko in patohistološko izboljšanje, popolne patohistološke remisije bolezni pa ne. Podobno navajajo tudi drugi avtorji, ki govorijo o vztrajanju kolagenoznega gastritisa s patohistološkega vidika $(1,2,5$, 7, 11, 17).

\section{Zaključek}

Kolagenozni gastritis je redka idiopatska in benigna bolezen v otroštvu. Od odrasle oblike se razlikuje po tem, da gre običajno za izolirano bolezen želodčne sluznice. Za bolezen je značilno neskladje med klinično benigno naravo bolezni in patohistološkim izvidom biopsijskih vzorcev želodčne sluznice.
Na možnost KG moramo pomisliti pri nepojasnjeni slabokrvnosti, bolečinah v žlički in drugih dispeptičnih simptomih ob endoskopsko ugotovljeni nodularni želodčni sluznici. Zaradi kronične narave bolezni moramo bolnike spremljati tako s kliničnega vidika kot tudi s ponavljanjem endoskopskih preiskav zaradi nadzora razširjenosti sluzničnih sprememb, predvsem morebitnega razvoja kolagenoznega kolitisa.

Sledenje posameznih bolnikov je zaradi redke pojavnosti bolezni pomembno tudi zaradi boljšega razumevanja prognoze, etiopatogeneze bolezni in odziva na različne vrste zdravljenja.

\section{Literatura}

1. Nielsen $\mathrm{OH}$, Riis LB, Danese $\mathrm{S}$, Bojesen RD, Soendergaard C. Proximal collagenous gastroenteritides: clinical management. A systematic review. Ann Med 2014; 46: 311-7.

2. Gopal P, McKenna BJ. The collagenous gastroenteritides: similarities and differences. Arch Pathol Lab Med 2010; 134: 1485-9.

3. Lan N, Shen B, Yuan L, Liu X. Comparison of clinical features, treatment, and outcomes of collagenous sprue, celiac disease, and collagenous colitis. J Gastroenterol Hepatol 2017; 32: 120-7.

4. Pardi DS. Diagnosis and management of microscopic colitis. Am J Gastroenterol 2017; 112: 78-85.

5. Kamimura K, Kobayashi M, Sato Y, Aoyagi Y, Terai S. Collagenous gastritis: Review. World J Gastrointest Endosc 2015; 7(3): 265-73.

6. Colletti RB, Trainer TD. Collagenous gastritis. Gastroenterology 1989; 97:1552-5.

7. Hijaz NM, Septer SS, Degaetano J, Attard TM. Clinical outcome of pediatric collagenous gastritis: case series and review of literature. World J Gastroenterol 2013; 19: 1478-84.

8. Al-Kandari A, Al-Alardati $\mathrm{H}$, Sayadi $\mathrm{H}, \mathrm{Al}-\mathrm{Ju}$ daibi B, Mawardi M. An unusual case of collagenous gastritis in a middle- aged woman with systemic lupus erythromatosis: a case report. J Med Case Rep 2014; 8: 278.

9. Stancu M, De Petris G, Palumbo TP, Lev R. Collagenous gastritis associated with lymphocytic gastritis and celiac disease. Arch Pathol Lab Med 2001; 125: 1579-84.

10. Gillett HR, Freeman HJ. Prevalence of celiac disease in collagenous and lymphocytic colitis. Can J Gastroenterol 2000; 14: 919-21.

11. Matta J, Alex G, Cameron DJS, Chow CW, Hardikar W, Heine RG. Pediatric collagenous gastritis and colitis: a case series and review of the literature. J Pediatr Gastroenterol Nutr 2018; 67: 328-34.
12. Suskind D, Wahbeh G, Murray K, Christie D, Kapur RP. Collagenous gastritis, a new spectrum of disease in pediatric patients: two case reports. Cases J 2009; 2:7511.

13. Lee YJ, Lee M, Kim DJ, Lee S, Hong J. Three case reports of collagenous gastritis in children: Lessons for an endoscopic and histologic approach to mucosal nodularity of the stomach. Medicine (Baltimore) 2019; 98: e14870.

14. Rosell-Camps A, Riera-Llodrá JM, ColomSegui M, Zibetti S, Amengual-Antich I. Collagenous gastritis in the pediatric age. Rev Esp Enferm Dig 2015; 107: 313-5.

15. Park S, Kim DH, Choe YH, Suh YL. Collagenous gastritis in a Korean child: a case report. J Korean Med Sci 2005; 20:146-9.

16. Hayashi S, Nishida T, Adachi S, Mima A, Inada M. Collagenous gastritis: a rare disease with distinctive endoscopic findings. Gastrointest Endosc 2018; 88: 186-7.

17. Kamimura K, Kobayashi M, Narisawa R, Watanabe H, Sato Y, Honma T, et al. Collagenous gastritis: endoscopic and pathologic evaluation of the nodularity of gastric mucosa. Dig Dis Sci 2007; 52: 995-1000.

18. Arnason T, Brown IS, Goldsmith JD, Anderson W, O'Brien BH, Wilson C, et al. Collagenous gastritis: a morphologic and immunohistochemical study of 40 patients. Mod Pathol 2015; 28 : 533-44.

19. Ma C, Park JY, Montgomery EA, Arnold CA McDonald OG, Liu TC, et al. A comparative clinicopathologic study of collagenous gastritis in children and adults: the same disorder with associated immune-mediated diseases. Am J Surg Pathol 2015; 39(6): 802-12.

20. Leiby A, Khan S, Corao D. Clinical challenges and images in $\mathrm{Gl}$ collagenous gastroduodenocolitis. Gastroenterology 2008; 135: 17327.

21. Bajwa RU, Joshi A, Heikenen JB. Successful treatment of collagenous gastritis in a child with a gluten-free diet. WMJ 2015; 114(6): 271-3.

22. Lim HW, Wong BY, Elkowitz D, Sultan K. An elderly patient's complete response to steroid therapy for collagenous gastritis. Ther Adv Chronic Dis 2018; 9(8): 143-6.

23. Lagorce-Pages C, Fabiani B, Bouvier R, Scoazec JY, Durand L, Flejou JF. Collagenous gastritis: a report of six cases. Am J Surg Pathol 2001; 25:1174-9.

24. Pain CE, Constantin T, Toplak N, Moll M, Iking-Konert C, Piotto DP, et al. Paediatric Rheumatology European Society (PRES) Juvenile Scleroderma Working Group. Clin Exp Rheumatol 2016; 34 Suppl 100(5): 200-6. 
Tjaša Nanut, dr. med.

Zdravstveni dom Ajdovščina, Ajdovščina, Slovenija

prof. dr. Nina Zidar, dr. med. Inštitut za patologijo,

Medicinska fakulteta Ljubljana, Ljubljana, Slovenija

mag. Darja Urlep, dr. med. (kontaktna oseba / contact person) Klinični oddelek za gastroenterologijo, hepatologijo in nutricionistiko,

Pediatrična klinika Ljubljana,

Bohoričeva 20, 1000 Ljubljana, Slovenija e-naslov: darja.urlep@gmail.com

prispelo / received: 28. 2. 2020

sprejeto / accepted: 22. 3. 2020

Nanut T., Zidar N., Urlep D. Kolagenozni gastritis pri otrocih. Slov Pediatr 2020; 27(3): 137-141. https://doi.org/10.38031/ slovpediatr-2020-3-06. 